\title{
Da denúncia à impunidade: um estudo sobre a morbi-mortalidade de crianças vítimas de violência
}

\author{
From complaints to impunity: \\ a morbidity and mortality profile \\ of children suffering violence
}

Romeu Gomes 1

1 Departamento de Ensino,
Instituto Fernandes Figueira,
Fundação Oswaldo Cruz.
Av. Rui Barbosa 716, 5o andar,
Rio de Janeiro, RJ
$22250-020$, Brasil.
Abstract This article analyzes complaints of violence against children and the procedures subsequent to their filing. The methodology, largely qualitative, was two-pronged, involving an analysi s of data from the year 1990 from the police precincts in Program Areas 1 and 5 in the city of Rio de Janeiro and a discussion on the follow-up of complaints five years after the events. The conclusi on was that motor vehicle acci dents are the most common cause of violence against children. Almost no information had been recorded about the circumstances in which the violent events occurred. Further, nothing had been done to el uci date the perpetrators' liability. Key words Violence; Morbidity; Mortality; Child Health

Resumo O artigo analisa denúncias de violência contra crianças, bem como o encaminhamento dado a essas denúncias. A metodologia do estudo, predominantemente qualitativa, leva em conta dois procedi mentos: (1) análise de dados de 1990 de delegacias de polícia das áreas programáticas números 1 e 5 do Município do Rio de Janeiro, e (2) discussão do encaminhamento dado às denúncias, após decorri dos cinco anos dos acontecimentos. Conclui-se que, entre outros eventos, os aci dentes de trânsi to predominam no conjunto dos dados. Também observa-se que as ocorrências pouco informam sobre as circunstâncias dos eventos violentos e praticamente nada foi feito para se apurar as responsabilidades de quem comete violência contra a criança. Palavras-chave Violência; Morbidade; Mortalidade; Saúde Infantil 


\section{Considerações iniciais}

Como observa Minayo (1994), no setor saúde, a violência vem sendo tradicionalmente abordada por meio de estudos de mortalidade e, precariamente, mediante informações de morbidade. A autora apresenta dados bastante significativos sobre o predomínio da violência enquanto causa de mortes de crianças e adolescentes no Brasil.

Entre as investigações que abordam especificamente mortalidade e morbidade por violência entre crianças e adolescentes, podemos destacar o estudo epidemiológico desenvolvido pelo Centro Latino-Americano de Estudos sobre Violência e Saúde da Fundação Oswaldo Cruz (Claves/ Fiocruz, 1994). Nesta investigação, foram levantados os registros das ocorrências de violências cometidas contra crianças e adolescentes na faixa etária de zero a 19 anos de idade, em todas as delegacias do Município do Rio de Janeiro, no ano de 1990.

Parte dos dados de morbidade dessa pesquisa é analisada em artigo de Assis \& Souza (1995). Nessa análise, as autoras apontaram para a existência de oito mil registros de eventos violentos cometidos contra a faixa etária de zero a 19 anos de idade, no ano de 1990, no Município do Rio de Janeiro. Nesse quadro, predominam os acidentes de trânsito e de transportes em 37\% das ocorrências; as agressões físicas, em $28 \%$; os roubos, furtos e suas tentativas, em $16 \%$ destes eventos.

No que diz respeito aos dados de mortalidade da pesquisa em questão, estes foram analisados no artigo de Souza \& Assis (1996). Segundo esses dados, em 1990, morreram 1.204 vítimas na faixa etária de zero a 19 anos por violência, no Município do Rio de Janeiro. No conjunto desses registros, predominam os homicídios, em 35\%; a remoção de cadáver, em $31 \%$; os acidentes de trânsito e transportes, em $17 \%$.

Dando continuidade a essa pesquisa, realizamos um estudo, de caráter predominantemente qualitativo, no Instituto Fernandes Figueira, da Fundação Oswaldo Cruz (IFF/Fiocruz, 1995), o qual passa daqui em diante a ser denominado de Estudo I. Nesse estudo procuramos discutir aspectos sociais relacionados às ocorrências de eventos de morbi-mortalidade de crianças, de zero a nove anos, vítimas de violência.

Na medida em que o Estudo I era predominantemente de caráter qualitativo, não tendo a preocupação de analisar a extensão dos dados, escolhemos a Área Programática 1 (AP 1) e a Área Programática 5 (AP 5) no conjunto das áreas trabal hadas na pesquisa do Claves/ Fiocruz. A escolha destas áreas programáticas ocorreu porque a AP 1 era a área de maior taxa de ocorrências (a de maior proporção entre o número de ocorrências e a população existente na mesma faixa etária estudada estimada para o mesmo ano, na relação para cem mil habitantes) e a AP 5 era a de maior número de ocorrências. Os denominadores das taxas foram calculados por estimativas com base na população dos censos de 1980 e 1991. Assim, a AP 5 se destaca no conjunto das APs pelo fato de ter o maior número absoluto de registros de ocorrência de eventos violentos, enquanto a AP 1 tem o maior número relativo desses registros, ou seja, proporcionalmente, em termos de população infantil, ele tem uma taxa maior do que todas as APs.

Na AP 1 foram incluídas as seguintes Delegacias de Polícia (DPs): 1 - Praça Mauá, 2 - Saúde, 3 - Castelo, 4 - Praça da República, 5 - Mem de Sá, 6 - Cidade Nova, 7 - Santa Tereza e 17 São Cristóvão. Já na AP 5, as DPs foram as seguintes: 33 - Realengo, 34 - Bangu, 35 - Campo Grande e 36 - Santa Cruz.

Vale ressaltar que a AP 1 , além de apresentar a maior taxa de ocorrências violentas, também é identificada, segundo os dados do Ministério da Saúde, como a área de maior taxa de mortalidade por violência no período de 1980 a 1992 (Assis et al., 1995; Souza et al., 1995).

Uma das explicações para a alta taxa da AP 1 em relação às demais áreas deve-se ao fato de haver nela "os agravos devido à grande circulação de pessoas no centro da cidade e os decorrentes da procura de hospitais desta área, por habitantes vitimados em outros municípios" (Assis et al., 1995:16).

Em termos de morbidade, o Estudo I baseou-se num vasto conjunto de tipos de eventos registrados nas delegacias de polícia, conforme podemos constatar na Tabela 1, com uma significativa predominância de ocorrências relacionadas a acidentes de trânsito e de transportes, nas duas áreas programáticas. Estes acidentes, apresentados na Tabela 2, também se destacam entre as ocorrências mortais. Neste artigo, nossa análise qualitativa se volta para os três primeiros eventos de morbidade (acidentes de trânsito/transportes, agressão sexual e abuso sexual) e os três primeiros de mortalidade (acidente de trânsito/transportes, remoção de cadáver e homicídio).

Os dois primeiros eventos de morbidade que constam da Tabela 1 , nas duas APs selecionadas, em termos de predominância, são os mesmos encontrados na pesquisa do Claves/ Fiocruz, para o conjunto das APs, ainda que 


\section{Tabela 1}

Tipos de eventos violentos mórbidos contra crianças de zero a nove anos de idade - AP 1 e AP 5 - Município do Rio de J aneiro - 1990.

\begin{tabular}{|c|c|c|c|c|}
\hline Evento violento & AP1 & AP5 & Total & $\%$ \\
\hline Acidentes de trânsito/transporte & 54 & 267 & 321 & 61,26 \\
\hline Agressão física & 22 & 48 & 70 & 13,36 \\
\hline Abuso sexual & 11 & 30 & 41 & 7,82 \\
\hline Desaparecimento & 11 & 12 & 23 & 4,39 \\
\hline Seqüestro & 06 & 09 & 15 & 2,86 \\
\hline Agressão envolvendo Arma de fogo & 04 & 07 & 11 & 2,10 \\
\hline Negligência/Abandono & 04 & 04 & 08 & 1,53 \\
\hline Mordedura de cão & 0 & 05 & 05 & 0,95 \\
\hline Expulsão da casa c/a mãe & 04 & 0 & 04 & 0,77 \\
\hline Envenenamento/Intoxicação & 03 & 01 & 04 & 0,77 \\
\hline Ameaça de seqüestro & 0 & 04 & 04 & 0,77 \\
\hline Roubo/Furto & 02 & 01 & 03 & 0,57 \\
\hline Embriaguez & 02 & 0 & 02 & 0,38 \\
\hline Desabamento & 02 & 0 & 02 & 0,38 \\
\hline Cabeçada de boi/cavalo & 0 & 02 & 02 & 0,38 \\
\hline Queimadura & 0 & 02 & 02 & 0,38 \\
\hline Troca de bebês & 02 & 0 & 02 & 0,38 \\
\hline Tentativa de homicídio & 02 & 0 & 02 & 0,38 \\
\hline Queda em parque de diversão & 0 & 01 & 01 & 0,19 \\
\hline Subtração de Incapaz & 0 & 01 & 01 & 0,19 \\
\hline Xingamento provocando nervosismo & 01 & 0 & 01 & 0,19 \\
\hline Total & 130 & 394 & 524 & 100 \\
\hline
\end{tabular}

Tabela 2

Distribuição dos eventos violentos mortais contra crianças de zero a nove anos de idade - AP 1 e AP 5 - Município do Rio de J aneiro - 1990

\begin{tabular}{lcccc}
\hline Evento violento & AP1 & AP5 & Total & $\%$ \\
\hline Acidente de trânsito/transporte & 08 & 20 & 28 & 34,57 \\
Remoção de cadáver & 06 & 08 & 14 & 17,29 \\
Homicídio & 09 & 02 & 11 & 13,58 \\
Queda & 05 & 02 & 07 & 8,64 \\
Encontro de cadáver & 04 & 02 & 06 & 7,41 \\
Queimadura & 03 & 04 & 04 & 6,17 \\
Afogamento & 0 & 01 & 01 & 4,94 \\
Agressão física & 0 & 0 & 01 & 1,23 \\
Intoxicação & 01 & 02 & 04 & 1,23 \\
Sem esclarecimentos & 02 & 43 & 81 & 4,94 \\
Total & 38 & & 100 \\
\hline
\end{tabular}


ocorram em proporções diferentes em relação aos seus respectivos conjuntos. Já no que se refere à mortalidade, enquanto no Estudo I os acidentes de trânsito, a remoção de cadáver e os homicídios são, respectivamente, a primeira, a segunda e a terceira causas de morte, na pesquisa do Claves/ Fiocruz aparecem os homicídios, a remoção de cadáver e os acidentes de trânsito como, respectivamente, a primeira, a segunda e a terceira causas mortais.

Essa diferença se deve, principalmente, ao fato de se tratarem de faixas etárias diferentes. Como no estudo do Claves a faixa foi de zero a 19 anos de idade, há um destaque para homicídio, porque nas faixas etárias de dez a 14 anos e de 15 a 19 anos de idade esta causa de mortalidade aumenta de forma significativa no Brasil (Souza, 1994) e no Rio de Janeiro em particular (Souza \& Assis, 1996).

No sentido de complementar o Estudo I, no período de outubro de 1995 a junho de 1996, realizamos outro recorte nos dados gerais da pesquisa Claves/Fiocruz já mencionada, com o objetivo de identificar os eventos consi derados violência doméstica cometidos na faixa etária de zero a cinco anos de idade. Este estudo receberá daqui em diante a denominação de Estudo II. A partir desse recorte, foram realizadas visitas nas delegacias de todas as APs. Buscamos, com o retorno ao campo de estudo, identificar o encaminhamento dado aos registros das denúncias, após decorridos cinco anos do acontecimento.

Em geral, a obtenção de novas informações nas delegacias apresentaram problemas. Grande parte das fichas de ocorrência estava arquivada em local de difícil acesso e nem todas as delegacias facilitaram esse acesso. Em razão dos problemas encontrados não foi possível realizarmos uma outra etapa prevista do levantamento no sentido de completar os dados até chegar aos nove anos de idade. Assim, no Estudo II, só foi possível acompanhar o encaminhamento de 106 ocorrências registradas, relacionadas à violência doméstica, na faixa de zero a cinco anos de idade. Do total dessas ocorrências, $80 \%$ relacionavam-se a eventos mórbidos e $20 \%$, a eventos mortais. O acompanhamento revelou que, desse conjunto de ocorrência, somente 24 viraram inquéritos e, destes, somente um, que se tratava de homicídio, tornou-se processo, sendo o pretenso agressor absolvido.

Faz-se necessário observar que, dos 106 registros de ocorrência, em apenas 31\% consta que foi realizado exame nas vítimas para fundamentar a denúncia. Outro dado a ser destacado se refere ao fato de que em apenas 32\% das ocorrência havia testemunha do evento cometido contra a criança. Estas observações, de uma certa forma, explicam o porquê de várias denúncias não virarem processos.

Tendo por base os Estudos I e II mencionados, configura-se este artigo, que tem como objetivo central analisar as circunstâncias em que ocorreram eventos violentos cometidos contra a criança no Município do Rio de Janeiro, valendo-se das ocorrências registradas nas delegacias de polícias no ano de 1990. O segundo objetivo consiste em identificar o encaminhamento dado aos registros das denúncias, após decorridos cinco anos.

Com esses objetivos, pretendemos, em primeiro lugar, fornecer subsídios para as ações preventivas no campo da violência cometida contra crianças. Na área da saúde pública, fazse necessário tornar mais visível o que está por trás dos atos violentos para que se possa meIhor atuar. Por outro lado, o estudo do próprio processo em que se registram as denúncias traz um maior entendimento sobre a forma como os dados foram obtidos. A análise do encaminhamento das denúncias após decorrido um tempo ressalta-se como de fundamental importância para que os Conselhos de Direitos da Infância e os Conselhos Tutelares possam ter um quadro sobre o que vem sendo feito na área dos direitos da infância e nele destacar ações a serem implementadas em face de uma realidade constatada.

\section{Metodologia}

O princípio metodológico que norteou nosso estudo foi o da pesquisa social de caráter qualitativo, baseando-se na possibilidade de se contemplar a dimensão do significado e da intencionalidade presente nos atos, nas relações e nas estruturas sociais, conforme propõe $\mathrm{Mi}$ nayo (1992). Por outro lado, por partilharmos da idéia de Minayo \& Sanches (1993), que apontam para a possibilidade de uma intercomplementaridade das abordagens quantitativa e qualitativa, utilizamos al guns dados de caráter quantitativo para delimitar o problema aqui analisado.

Assim, no Estudo I, tomando como base a faixa etária de zero a nove anos de idade, recortamos os dados das duas áreas programáticas de maior significado no conjunto das ocorrências (AP 1 e AP 5), conforme mencionamos na introdução deste trabalho. Em seguida, selecionamos os três primeiros eventos violentos registrados nos dados de morbidade e os três nos de mortalidade. Ao todo foram contempla- 
das 432 ocorrências de eventos violentos mórbidos e 53 eventos violentos mortais na análise qualitativa

Essas ocorrências já se encontravam em banco de dados do Claves. Cada uma delas estava registrada em uma ficha, que continha duas partes. Na primeira, havia informações sobre: vítima, agressor, testemunhas, local do evento e comunicante da ocorrência. Já a segunda parte continha uma descrição de como ocorreu o evento (mecânica do evento). Os aspectos da primeira parte já tinham sido estudados na investigação do Claves (1994), compondo um perfil epidemiológico do quadro de morbi-mortalidade, ao passo que a segunda parte era de maior interesse para o presente estudo, uma vez que nela seria possível compreendermos em que circunstâncias e por que motivos ocorrem atos violentos contra a criança. Por ser de natureza mais descritiva, seria um campo da ficha que se prestaria mais a uma análise qualitativa.

Analisamos a descrição da mecânica do evento baseados na Técnica de Análise de Conteúdo - Modalidade Temática (Bardin, 1979), seguindo as seguintes fases: pré-análise (organização do material de análise); exploração do material (com sucessivas leituras) e tratamento dos resultados. Valendo-nos dessa técnica, o nosso tratamento dos resultados foi realizado tendo por base núcleos de sentido presentes nos registros de ocorrência, encontrados na fase de exploração do material. Devido à precariedade da informação registrada na descrição do evento, os núcleos de sentido só se configuraram a partir da articulação entre descrição da mecânica do evento e as informações sobre as vítimas e os agressores, presentes na primeira parte da ficha de ocorrência.

Em relação ao Estudo II , como já mencionamos, realizou-se um trabal ho de campo em delegacias das APs, onde procuramos fazer um acompanhamento de ocorrência sobre violência doméstica, entendida neste estudo como os eventos violentos ocorridos no domicílio da vítima ou aqueles, independente do local de ocorrência, praticados por parentes próximos da vítima. Dentro de cada AP, selecionamos delegacias de polícia que tinham casos de violência doméstica registrados contra crianças na faixa de zero a cinco anos de idade. Ao todo, visitamos 23 delegacias, em todas as APs, contemplando o estudo de 105 registros de ocorrência.

A observação realizada no campo - envolvendo contatos com responsáveis pelos registros, visitas a arquivos e estudo em geral do fluxo de tramitação de cada registro - foi registra- da em um relatório e com base neste procuramos pontuar aspectos que contribuíram ou não para um encaminhamento das denúncias. Estes dados, de uma certa forma, serviram para configurarmos o que na prática se fez com as ocorrências registradas.

Em síntese, em termos metodológicos, houve recortes com base numa abordagem quantitativa para se realizarem os dois estudos e valendo-nos destes recortes procuramos realizar uma análise qualitativa. No interior desta análise, apoiados em Minayo (1992) e Goldenberg (1997), direcionamos o nosso foco para a complexidade dos fatos registrados e não para extensão dos mesmos. Assim, a nossa discussão que segue procura abordar, de uma forma descritiva, a especificidade dos registros, procurando interpretá-los à luz de eixos de discussão configurados pelos núcleos de sentidos presentes nas narrativas das descrições dos eventos.

\section{A nálise das denúncias \\ e de seu encaminhamento}

\section{As denúncias em geral}

A análise qualitativa das denúncias de eventos violentos que vitimizaram crianças, presentes nos boletins de ocorrência, revela uma constatação que atravessa as duas áreas programáticas (APs) e os tipos de eventos estudados. Trata-se da ausência de dados, que se configura pelo fato de alguns itens desses boletins terem informações incompletas ou pela ausência das mesmas. Isto se percebe mais facilmente nas ocorrências relacionadas aos eventos mortais. Nestas, os agressores não são qualificados e as mecânicas do evento, segunda parte do boletim, geralmente explicita o que aconteceu, mas não aparece como aconteceu.

Em termos de ocorrências relativas à morbidade, há diferenças no registro das informações entre as duas APs quanto aos dados do agressor. Na AP 1, há um campo específico no boletim de ocorrência para se caracterizar o agressor, enquanto na AP 5 este campo está ausente. Nesta última AP, quando há informações sobre o agressor, estas se encontram registradas na parte referente à mecânica do evento. Ainda nesta $A P$, ao contrário da $A P 1$, não há espaço em que são registrados dados sobre testemunhas da ocorrência. Entretanto, o fato de a AP 1 ter um maior número de campos nos boletins de ocorrência não significa que esta área sempre tenha informações mais completas. Nela também são comuns as lacunas de informações. 
Assim, fica nítida, no conjunto dos dados estudados, a má qualidade do registro das denúncias, principalmente no que se refere à descrição da mecânica do evento. A redação desta parte é bastante lacunar. As informações são, no mínimo, insuficientes para compreendermos como ocorreram os fatos. Esta ausência de dados, de uma certa forma, compromete uma análise qualitativa mais apurada sobre as ocorrências registradas.

\section{Os acidentes de trânsito e de transporte}

Nos registros de acidentes de trânsito e de transporte, percebemos que os atropelamentos, de longe, apresentam-se como os eventos mais comuns nas duas áreas. Estes acidentes costumam ocorrer em via pública movimentada. Principalmente nas ocorrências de acidentes não mortais, percebe-se que há casos em que o atropelador socorre a criança atropelada. Apesar de ser comum esse tipo de socorro, há registros que não especificam quem prestou socorro e há vários casos em que o motorista fugiu após o acidente.

Nos registros dessas ocorrências, a fatalidade se identifica como um principal núcleo de sentido. A fatalidade do acidente, principalmente nos que não têm como conseqüência a morte da vítima, é sugerida pelas narrativas de situações em que as crianças atravessam as ruas descuidadamente ou correndo sem prestar a atenção ao veículo que as atropela. Entre estas narrativas, a título de ilustração, destacamos as seguintes:

"Segundo o agressor, a vítima em dado momento saíra da dianteira de um outro veículo e bruscamente tentara atravessar a rua, na ocasião que não pode desviar ou mesmo freiar indo atropelar o referido. Conduziu a vítima ao HMSA [Hospital Municipal Salgado Filho]" (Ocorrência no 14-251/AP 1, evento não mortal).

“Enquanto o atropelador ultrapassava um ônibus, a vítima tentava atravessar a rua. Um não viu o outro e a vítima foi atropelada" (Ocorrência no 12-8040/ AP 5, evento mortal).

"A vítima brincava na cal çada quando atravessou a rua inadvertidamente efoi atropelada" (Ocorrência no 4-7578/ AP 5, evento não mortal).

"A vítima, inesperadamente, saiu de trás de um carro ali parado, não dando para evitar o acidente" (Ocorrência no 56-652/ AP 1, evento não mortal).

"Vítima veio para atravessar a rua correndo e por trás de um caminhão, não sendo possível evitar o fato. O motorista a socorreu e a levou para o HP II, ondefaleceu" (Ocorrência no 338644, evento mortal).
“O motorista da moto vinha em velocidade reduzida e a vítima vinha solta das mãos da mãe e de repente correu não dando tempo para queo motorista parassea moto. O motorista socorreu a vítima" (Ocorrência no 35-336/ AP 1, evento não mortal).

Há casos em que, se considerarmos o fato de ser o atropelador quem mais socorre a vítima, a fatalidade sugerida pode ser vista também como um possível fator atenuante em favor do motorista que praticou o atropelamento. Aprofundando mais a reflexão sobre esse núcleo de sentido presente nos registros, podemos concluir que essa fatalidade, na realidade, pode ser conseqüência de várias situações, tais como: excesso de velocidade dentro da malha urbana; condições ruins de vias públicas que exigem dos motoristas manobras arriscadas e negligência e desrespeito às normas de trânsito. Por outro lado, a negligência de pais e responsáveis também não pode ser descartada como possível causa dos atropelamentos.

Outro núcleo de sentido que configura os acidentes aqui abordados diz respeito à alta velocidade e/ ou má direção. Podemos ilustrá-los baseados nos seguintes registros:

“O atropelador estava evadindo-se do local quando foi impedido pelo PM; a vítima estava atravessando a rua com sua mãe quando fora colhida pelo vé́culo" (Ocorrência no 57-653/ AP 1 , evento não mortal).

"Segundo a testemunha, o acusado conduzia a moto em grande vel ocidade, não conseguindo se desviar da vítima" (Ocorrência no 17553/ AP 5, evento não mortal).

"O auto atropelador descontrolou-se em uma curva, vindo a subir na calçada e atingindo a vítima" (Ocorrência no 26-8935/AP 5, evento mortal).

"Segundo o comuni cante, o atropelador vinha de Santa Cruz e, ao avançar o sinal vermeIho, colheu a vítima que foi socorrida pelo próprio, conduzindo-a ao HERF" (Ocorrência no 19-7807/ AP 5).

Nestes registros, costuma aparecer a culpabilização de motoristas. A alta velocidade ou má direção de veículos são atribuídas por testemunhas ou por policiais que comunicam a ocorrência. A fuga dos agressores, após o atropelamento, também é comum nestes casos.

\section{As agressões físicas}

A força física é o instrumento mais comum deste tipo de evento que pode comprometer a saúde da criança. Mas há também armas brancas, objetos cortantes e projétil de arma de fogo (PAF) registrados como instrumentos de 
agressão. Nestes casos, os comunicantes mais comuns das denúncias são a mãe da vítima e policiais militares. Parentes e conhecidos da criança vitimizada são os agressores que mais se destacam no conjunto dos registros.

O domicílio da vítima ou lugar a ele próximo é onde mais freqüentemente se dão as ocorrências. Especificamente na AP 1, a via pública concorre com o local do domicílio, sendo a primeira também constantemente registrada como local de ocorrência; assim, é comum aparecerem pessoas desconhecidas da vítima registradas como agressoras. Mas, em geral, nas duas áreas, os agressores são parentes ou conhecidos das crianças vitimizadas. Dentre eles, destacam-se os próprios responsáveis das crianças como os mais citados. Há também registros de policiais militares como agressores.

Um dos núcleos de sentido que podemos ressaltar no conjunto destas ocorrências se refere a conflitos familiares, que em alguns casos envolvem brigas entre parceiros e se associam ao uso de álcool. Nestas ocorrências, comumente os pais ou os padrastos aparecem como agressores. Seguem exemplos dessas situações:

"Segundo a comunicante, depois de uma discussão por motivos torpes, a mesma foi atacada, juntamente com sua filha, a socos e pauladas pel os parentes do pai de sua filha" (Ocorrência no 49-6750/ AP 5).

“O agressor teve um desentendimento com a esposa, tendo em seguida passado a agredir a filha com uma correia" (Ocorrência no 516791/ AP 5).

“O agressor é ex-companheiro da mãe da vítima. A mãe da vítima declarou que o agressor ingere bebida alcoól ica evai à sua resi dência somente para agredi-la. Aos 02/01/90, o agressor chega de S. P. e, com sintomas de embriaguez, agride a vítima. A vítima foi medicada..." (Ocorrência no 42-387/ AP 1).

"Segundo a comunicante, seu esposo estava embriagado e passou a agredir a todos dentro decasa. Que não éa primeira vez queisso acontece" (Ocorrência no 99-7901/ AP 5).

Há registros de agressões, a exemplo das narrativas abaixo, que também apontam para o núcleo de sentido relacionado a conflitos entre vizinhos. Em geral, estes registros descrevem casos de crianças que são agredidas fisicamente por conta de brigas travadas entre seus responsáveis e vizinhos. A exemplo disto, ressaltamos as seguintes descrições:

“A vítima, quando desenvolvia sua tarefa, ao passar pelo local, encontrou com sua vizinha que, diga-se de passagem, é seu desafeto, eapós trocas de insultos, agrediu com a pá. Na oca- sião, sua filha de 1 mês que estava em seus braços, caiu ao chão, batendo com a cabeça" (Ocorrência no 51-591/ AP 1).

“Trata-se deagressão física envol vendo duas famílias que residem próximas uma da outra. As famílias foram medicadas..." (Ocorrência no 95-7757/ AP 5).

As agressões físicas também têm o sentido de maus-tratos e/ ou negligência. Nestes casos, como pode ser constatado nos registros que se seguem, a característica central se refere ao abandono de crianças por algum tempo, fazendo com que fiquem entregues à própria sorte. Em geral, são os parentes das crianças que as deixam abandonadas, ma há casos de abandono em instituições educacionais.

"Segundo testemunhas, a mãe da menor trabal ha desde Julho/89 em sua resi dência, éal coóI atra e costuma viajar sempre com a criança e, semprequeretorna, a menor apresenta sinais de maus-tratos e abandono e através de uma tia, souberam as testemunhas quea agressora teve quatro fil hos que morreram por maus-tratos" (Ocorrência no 60-601/AP 1).

"Segundo a comunicante, sua filha foi vitimada por maus-tratos, sendo espancada pela tia, irmã de seu ex-marido, que mora no local do fato. Esclareceu a comunicante que a menor e seu outro filho estão sob a guarda do pai, mas que este passou à vida do crime, deixando os menores com a irmã, que constantemente pratica agressi vidade com el es" (Ocorrência no 628673/ AP 5).

"Segundo o comunicante, deixou seu filho no jardim de infância eà noite quando seu pai foi pegá-lo, o mesmo estava cheio de mordidas..." (Ocorrência no 115-0025045/ AP 1).

$\underline{\text { Homicídios e remoção de cadáver }}$

Os homicídios ocorreram em vias públicas ou no próprio domicílio da vítima. Os instrumentos utilizados que mais aparecem nos registros das ocorrências são projéteis de arma de fogo (PAF) e o emprego de força física. Há registros de crianças que dão entrada em hospitais agonizando, vindo a falecer logo em seguida. Nestes casos, o que ocorreu antes da internação não se encontra registrado. Também há registros de homicídios associados a abuso sexual. Em termos de destaque, há uma constatação de afogamento classificada como suspeita de homicídio. Outro destaque se refere ao registro do caso de um pai que atira seu filho do nono andar de um prédio e, em seguida, também se atira.

Os registros de homicídios envolvendo PAF apontam para situações em que as crianças fo- 
ram vítimas de brigas entre traficantes e foram atingidas por bala perdida, em batidas policiais. Porém, o que mais se encontra registrado é apenas que a vítima foi baleada, não constando nenhuma outra informação. A falta de elementos para se perceber a mecânica dos eventos é uma tônica nos registros destes.

As remoções de cadáver, em geral, caracterizam-se por casos em que a polícia é solicitada para remover corpos de fetos ou de crianças sem vida. Há registros que classificam a ocorrência como possível homicídio. Em outros constam acusações de que as crianças foram vítimas de imperícia no atendimento médico. Há também registros que apenas mencionam que foi encontrado o cadáver. Quanto aos casos únicos, há uma ocorrência em que se registram sinais clínicos de afogamento e outra que aponta para o fato de a vítima ter sofrido choque elétrico em seu domicílio.

Comumente, nos boletins das ocorrências dos homicídios e das remoções de cadáver de crianças, não há informações sobre os agressores, as situações em que ocorreram e sobre a própria vítima. Na maioria dos registros destas ocorrências nada consta sobre a causa mortis. Uma análise qualitativa mais apurada sobre os homicídios e as remoções de cadáver ficou prejudicada em razão das inúmeras ausências de dados sobre como realmente aconteceu o evento. Se fosse apontado um núcleo de sentido para estes registros, o único possível seria a invisibilidade do fato.

\section{Abuso sexual}

Os abusos sexuais variam de tentativas de atentado ao pudor até estupros cometidos contra meninas e meninos. Há um registro em que a vítima tinha apenas um ano de idade. Quanto aos autores dos abusos, estes variam entre parentes, vizinhos e desconhecidos. Entre os conhecidos, há casos de pais e padrastos serem autores de violência sexual contra enteados ou enteadas.

As descrições dos abusos sexuais apontam para dois núcleos de sentido. O primeiro deles se refere a aliciamento, caracterizando-se por casos em que o agressor, parente ou conhecido da vítima, vale-se de expressões de afeto ou de promessa de brinquedos para praticar atos sexuais com a criança. Como exemplos, podem ser destacados os seguintes registros:

“Menina foi à igreja com a avó. Lá, o pastor a chamou ao sótão, onde deveriam estar "bolas". Chegando no sótão, o pastou tentou penetrar a menina com o dedo" (Ocorrência no 1178074/AP 5).
“Segundo o expediente no qual a mãe da vítima, por seu advogado, apresenta queixa de crime de atentado violento ao pudor contra seu esposo, o qual manteve com seu filho menor coito anal" (Ocorrência no 83-8411/AP 1).

"Segundo a comunicante, sua neta encontrava-se na guarda de seu pai, entregue pela mãe, tendo este permaneci do com a mesma no espaço compreendido entre o dia 25/12/89 às $14 \mathrm{~h}$ do dia $01 / 01 / 90$, sendo então entregue à comunicante, apresentando si ntoma de estar bastante debilitada, sendo que uma das filhas da comunicanteverificou queas partes íntimas da menina estavam inchadas, eque, ao ser medicada, constatou a violência contra a menor conforme Boletim de Atendimento Médico - ruptura de hímen, etc. PS: a menor está sob tutela da avó" (Ocorrência no 74-7109/AP 5).

Outro núcleo de sentido presente nos registros de abuso sexual diz respeito ao uso da força. Nestes casos, o agressor emprega força física para manter a relação sexual com a vítima. Entre estes, destacam-se os seguintes:

"O autor écunhado da comunicantee reside no mesmo endereço dela e da vítima. A cunhada da comunicante presenciou o agressor mandar que o menor chupasse o seu pênis. O fato só foi contado no dia de hoje, pois, tanto a vítima, como a testemunha temeram retaliações do autor que é pessoa violenta" (Ocorrência no 817359/ AP 5).

“A mãe da vítima declara que um colega da vítima agarrou e praticou violência sexual com a vítima. A maneira de como se consumou a violência não ficou esclarecida" (Ocorrência no 48-453/ AP 1).

“A mãe da menor, que também foi vítima, acordou com um elemento à beira de sua cama que Ihe acordara obrigando-a a amarrar seu marido que estava dormindo do seu lado. Sob ameaça de armas, obrigou a comunicante a acordar a filha, passando a seviciar-se da criança na presença dos pais. Ele forçou a menina permanecer de pernas abertas e tentou penetração com o pênis na vagina da menor. Em seguida, estuprou a comuni cante sob o ol har do marido, da menor edeoutro filho de 5 anos. Em se guida, fugiu levando os produtos do roubo" (Ocorrência no 78-7386/AP 5).

\section{O desfecho das denúncias}

Por meio do reexame dos boletins de ocorrências, realizado no retorno às delegacias, observou-se inicialmente que a violência doméstica não escolhe sexo, cor, nem classe social. Este tipo de violência se configura de forma diferente de outros tipos que comumente atingem 
pessoas pobres e não brancas. Neste estudo constatou-se uma parcela significativa de vítimas de cor branca. Este dado pode significar uma tendência maior para a denúncia nas classes sociais mais favorecidas, apesar da lei do silêncio que ainda prevalece em torno da violência doméstica.

O desfecho das denúncias, após decorridos cinco anos do seu registro, foi desolador. Os dados revelam que poucos inquéritos foram instaurados e apenas um virou processo, caso em que o réu foi considerado inocente, provavelmente por falta de provas. Alguns inquéritos foram arquivados e outros continuavam em andamento. Estes últimos possivelmente serão arquivados, em razão do tempo.

Ficou nítido que a falta de provas foi um dos fatores que mais contribuiu para que as denúncias não se transformassem em processo criminal. Em muitos casos, isto ocorreu por conta da ineficiência da própria polícia, por não ter realizado os exames necessários para a caracterização do crime e por nem sempre ter se preocupado com a existência de testemunhas. Assim, em várias ocorrências, não se conseguiu obter provas da autoria e materialidade do crime para a instauração de inquérito policial.

A análise dos dados deste estudo aponta para um núcleo de sentido central que diz respeito ao desfecho das denúncias registradas: a impunidade. As anotações do trabalho de campo revelam que a impunidade decorre do descaso e da ineficiência das autoridades policiais, da desorganização das delegacias de polícia e, ainda, da inércia dos representantes legais das crianças vítimas da violência doméstica. Esta inércia se configura quando estes representantes, quando não são os agressores, não requerem a instauração de inquérito policial ou ação penal. Mas será que os representantes legais são suficientemente esclarecidos para procederem adequadamente? Quando esclarecidos, será que dispõem dos meios necessários para seguirem as vias crucis dos serviços públicos?

Da denúncia até a instauração de inquérito ou ação penal, a trajetória é longa. Percorrê-la significa empreender uma aventura por labirintos que nem sempre levam ao final do caminho. O processo vivenciado neste estudo remete a uma questão fundamental: se, para aqueles que participaram deste estudo, foi difícil acompanhar o que aconteceu com os registros das denúncias, ainda que com uma assessoria na área do Direito e com uma formação em ciências sociais, o que dizer em relação ao cidadão comum que tenta defender os direitos da criança?

\section{Considerações finais}

A análise qualitativa dos dados revela que os registros das ocorrências expressam núcleos de sentido. Entre estes, a invisibilidade do fato ea impunidade são os que mais se destacam. Estes núcleos, de uma certa forma, encontram-se articulados, uma vez que, em muitos casos, a ausência de informações, que não torna visíveis as circunstâncias em que ocorreram os eventos violentos, poderia estar por trás do fato de praticamente nada ter sido feito em face das denúncias. Diante deste quadro, concluímos, entre outros aspectos, que a impunidade é tão violenta quanto os crimes praticados contra as crianças.

Junto à essa conclusão geral, aprofundando mais a leitura das denúncias e do encaminhamento a elas dado, a análise aponta para questões que podem servir de base para uma reflexão mais ampla sobre o status de criança, principalmente pobre, na atual sociedade.

Será que o aparelho público está pouco estruturado quanti-qualitativamente para conseguir uma boa qualidade nos registros dessas ocorrências e no seu encaminhamento? Será que a forma incompleta dos registros e o nãotratamento adequado ao encaminhamento das denúncias revelam a indiferença sobre os casos ocorridos?

A afirmativa para a primeira questão não pode ser descartada. Sabe-se que as condições em que se encontram as polícias civil e militar, assim como o aparelho público em geral, são, no mínimo, ruins. Faltam recursos financeiros, pessoal qualificado, equipamentos e, principalmente, a mobilização das pessoas para que essas instituições possam desempenhar seus papéis na sociedade. Essas condições, ou meIhor dizendo, a falta delas, são reflexos de um Estado que, no campo social, pouco investe ou, em alguns momentos, age de forma incompetente.

Por outro lado, em relação ao fato de haver indiferença sobre as ocorrências (segunda questão levantada), a afirmativa é a opção bastante plausível para que se retrate melhor a realidade detectada. Nas denúncias e no seu encaminhamento encontram-se reflexos sociais que vão para além das polícias civil e militar, enquanto instituições. A inexistência de testemunhas, em grande parte das ocorrências; a não-indicação do agressor em alguns casos; a falta de apuro nas denúncias; informações incompletas e a pouca resolutividade no período pós-denúncia podem significar que as crianças pobres pouco valem na sociedade. Como observa Faleiros (1995), os atos de vio- 
lência cometidos contra crianças se inserem no arcabouço cultural e institucional em que as relações cotidianas entre adultos e crianças têm como cerne a fabricação da obediência. Castigar, reprimir ou fazê-las aprender uma lição fazem parte do jogo de torná-las dóceis para que o poder do adulto sobre elas se imponha.

Se as crianças em geral vivem ou sofrem essa sina, o que se pode falar daquelas que são pobres? Estas sofrem em maior grau os efeitos da dominação. Entregues à própria sorte, estes atores, quando conseguem sobreviver, vivenciam uma trajetória de mais violência. Em geral, serão candidatos a: serem desnutridos; sofrerem maus-tratos; não freqüentarem a escola ou nela não conseguirem permanecer; terem a rua como espaço de moradia e/ ou de trabalho e possuírem a sua saúde em geral comprometida.

Os dados também revelam as contradições da sociedade brasileira atual no trato da infância e da adolescência. Na Constituição de 1988, em seu artigo 227, os direitos da criança e do adolescente são assegurados com absoluta prioridade. Esses direitos são mais bem explicitados e seus mecanismos de viabilização são definidos na Lei 8.069 de 1990 (O Estatuto da Criança e do Adolescente). No entanto, um recorte da realidade da criança analisado neste estudo mostra que o que acontece é bem diferente dos preceitos legais.

Parece que, na prática, a sociedade, ao invés de proteger os direitos das crianças, conforme preconizam suas leis, protege seu agres-

\section{Agradecimento}

O autor agradece aos bolsistas de iniciação científica Ana Beatriz Braz de Almeida, Isabella Brizzante Ecteins e Márcio Solter, que participaram da pesquisa que deu origem ao presente artigo. Pesquisa realizada com bolsa de pesquisador visitante (Fiocruz/ Faperj) e bolsas de iniciação científica (Fiocruzl CNPq). sor, desqualificando as crianças por serem simplesmente crianças. Em se tratando de eventos violentos não mortais, principalmente, cometidos contra a infância, a indiferença e/ ou a banalização é maior. Nestes casos, a violência é percebida como fenômeno natural ou naturalizado.

Apesar dessas constatações, observamos atualmente um movimento que tenta desqualificar os preceitos legais vigentes sobre a proteção da infância e da adolescência. Como se esta proteção, que nem sempre sai do texto para a prática, fosse responsável pela delinqüência, cuja raiz é bem mais profunda. É um movimento que vai em direção da minimização dos direitos numa onda em que se busca um Estado 'mínimo'.

A violência retratada nas ocorrências aqui estudadas e a violência do não-encaminhamento das denúncias servem como alerta para os desafios que as instituições e grupos sociais devem enfrentar para que se superem as contradições nesse campo, sob o risco de se potencializar mais a violência.

Caminhando nessa perspectiva, a saúde pública precisa se voltar para o desenvolvimento de ações conjuntas com outros setores, não se limitando a espaços tradicionalmente ocupados para as suas ações. Deve ter como um exemplo de outros campos de atuação o seu envolvimento na criação e na implementação dos Conselhos Municipais Tutelares, para que possa cada vez mais contribuir para a mudança do quadro atual de agravos à saúde de crianças e adolescentes.

\section{Referências}

ASSIS, S. G. \& SOUZA, E. R., 1995. Morbidade por violência em crianças e adolescentes do Município do Rio de Janeiro. Jornal de Pediatria, 71:303-312.

ASSIS, S. G.; SOUZA, E. R. \& SILVA, C. M. F. P., 1995. Violência no Município do Rio de Janeiro, Brasil: I. O Impacto e Tendência da Mortalidade de Crianças de 0 a 9 Anos. Rio de Janeiro: Centro LatinoAmericano de Estudo sobre Violência e Saúde "Jorge Carelli", Escola Nacional de Saúde Pública, Fundação Oswaldo Cruz. (mimeo.)

BARDIN, L., 1979. Análise de Conteúdo. Lisboa: Edições 70 . 
CLAVES (Centro Latino-Americano de Estudos sobre Violência e Saúde "Jorge Carelli"), 1994. Estudo Sócio-Epidemiológico da Morbi-Mortalidade de Crianças e Adolescentes Vítimas deViolência, no Município do Rio de Janeiro ena Baixada Fluminense. Projeto de pesquisa. Rio de Janeiro: Centro Latino-Americano de Estudo sobre Violência e Saúde "Jorge Carelli", Escola Nacional de Saúde Pública, Fundação Oswaldo Cruz. (mimeo.)

FALEIROS, V. P., 1995. Violência contra a infância. Sociedadee Estado, 10:475-490.

GOLDENBERG, M., 1997. A Arte de Pesquisar: Como Fazer Pesquisa Qualitativa em Ciências Sociais. Rio de Janeiro: Record.

IFF (Instituto Fernandes Figueira), 1995. A Dimensão Social da Morbimortalidade de Crianças Vítimas deViolência. Projeto de pesquisa. Rio de Janeiro: Instituto Fernandes Figueira, Fundação Oswaldo Cruz. (mimeo.)

MINAYO, M. C. S., 1992. O Desafio do Conhecimento: Pesquisa Qualitativa em Saúde. São Paulo: Hucitec/Rio de Janeiro: Abrasco.
MINAYO, M. C. S., 1994. A violência social sob a perspectiva da saúde pública. Cadernos de Saúde Pública, 10 (Supl. 1): 07-18.

MINAYO, M. C. S. \& SANCHES, O., 1993. Quantitativo-Qualitativo: oposição ou complementaridade? Cadernos de Saúde Pública, 9:239-269.

SOUZA, E. R., 1994. Homicídios no Brasil: o grande vilão da saúde pública na década de 80 . Cadernos deSaúdePública, 10 (Supl. 1):45-60.

SOUZA, E. R. \& ASSIS, S. G., 1996. Mortalidade por violência em crianças e adolescentes no Município do Rio de Janeiro. Jornal Brasileiro de Psiquiatria, 45:85-94.

SOUZA, E. R.; ASSIS, S. G. \& SI LVA, C. M. F. P., 1995. Violência no Município do Rio de Janeiro, Brasil: II. O Impacto eTendência da Mortalidadeem Adolescentes de 10 a 19 anos. Rio de Janeiro: Centro Latino-Americano de Estudo sobre Violência e Saúde "Jorge Carelli", Escola Nacional de Saúde Pública, Fundação Oswaldo Cruz. (mimeo.) 